\title{
Osteoclasts expressing the measles virus nucleocapsid gene display a pagetic phenotype
}

\author{
Noriyoshi Kurihara, ${ }^{1}$ Sakamuri V. Reddy, ${ }^{1}$ Cheikh Menaa, ${ }^{1}$ Dirk Anderson, ${ }^{2}$ \\ and G. David Roodman ${ }^{1,3}$ \\ ${ }^{1}$ Department of Medicine/Hematology, University of Texas Health Science Center, San Antonio, Texas 78229, USA \\ ${ }^{2}$ Immunex Corp., Seattle, Washington 98101, USA \\ ${ }^{3}$ Veterans Administration Medical Center, San Antonio, Texas 78284, USA
}

Address correspondence to: G. David Roodman, Research (151), Audie Murphy Veterans Administration Hospital, 7400 Merton Minter Boulevard, San Antonio, Texas 78284, USA.

Phone: (210) 617-5319; Fax: (210) 567-4705; E-mail: roodman@uthscsa.edu.

Received for publication September 20, 1999, and accepted in revised form January 19, 2000.

\begin{abstract}
Osteoclasts (OCLs) in Paget's disease are markedly increased in number and size, have increased numbers of nuclei per multinucleated cell, and demonstrate increased resorption capacity and increased sensitivity to $1,25-(\mathrm{OH})_{2} \mathrm{D}_{3}$, the active form of vitamin $\mathrm{D}$. These cells also contain nuclear inclusions, reminiscent of those seen in paramyxovirus-infected cells, which cross-react with antibodies to measles virus nucleocapsid (MVNP) antigen. To elucidate the role of MV in the abnormal OCL phenotype of Paget's disease, we transduced normal OCL precursors with retroviral vectors expressing $M V N P$ and the MV matrix (MVM) genes. The transduced cells were then cultured with $1,25-(\mathrm{OH})_{2} \mathrm{D}_{3}$ for 14 or 21 days to induce formation of OCL-like multinucleated cells. The MVNP-transduced cells formed increased numbers of multinucleated cells, which contained many more nuclei and had increased resorption capacity compared with multinucleated cells derived from empty vector-transduced (EV-transduced) and $M V M$-transduced or normal bone marrow cells. Furthermore, $M V N P$-transduced cells showed increased sensitivity to $1,25-(\mathrm{OH})_{2} \mathrm{D}_{3}$, and formed OCLs at concentrations of $1,25-(\mathrm{OH})_{2} \mathrm{D}_{3}$ that were 1 $\log$ lower than that required for normal, EV-transduced, or $M V M$-transduced cells. These results demonstrate that expression of the MVNP gene in normal OCL precursors stimulates OCL formation and induces OCLs that express a phenotype similar to that of pagetic OCLs. These results support a potential pathophysiologic role for MV infection in the abnormal OCL activity and morphology that are characteristic of pagetic OCLs.
\end{abstract}

J. Clin. Invest. 105:607-614 (2000).

\section{Introduction}

Paget's disease of bone is a chronic focal skeletal disorder, affecting $1-2 \%$ of the population over the age of 45 , in which the primary cellular abnormality resides in the osteoclast (OCL) (1). OCLs from Paget's patients express a unique phenotype. They are markedly increased in number and size and have increased numbers of nuclei per multinucleated cell, demonstrate increased resorption capacity, and are hypersensitive to $1,25-(\mathrm{OH})_{2} \mathrm{D}_{3}$, the active form of vitamin $\mathrm{D}(2,3)$. Immunocytochemical studies have shown that pagetic OCLs contain paramyxoviral-like nuclear inclusions that cross-react with antibodies to measles virus (MV), respiratory syncytial virus, and canine distemper virus nucleocapsid antigen (4-7). In situ hybridization studies have detected expression of MV nucleocapsid (MVNP) transcripts in OCLs from patients with Paget's disease $(8,9)$. In addition, OCL precursors and circulating peripheral blood cells from Paget's patients express MVNP transcripts (10). However, the role MV infection plays in the abnormal OCL phenotype in Paget's disease is unknown.
We transduced MV genes into normal OCL precursors to determine their role in the abnormal OCL activity in Paget's disease. In particular, we constructed retroviral vectors expressing the MVNP and the MV matrix (MVM) genes, and transduced these constructs into normal marrow cells to determine whether the expression of a particular MV gene induced a phenotype in OCLs that was very similar to the phenotype of OCLs from Paget's patients. Results of these studies demonstrated that expression of the $M V N P$ gene, but not the $M V M$ gene, in normal OCL precursors enhanced formation of OCLs that had many of the characteristics of pagetic OCLs.

\section{Methods}

Subjects and cell preparation. The Institutional Review Board of the University of Texas Health Science Center at San Antonio approved these studies. Bone marrow cells were aspirated from the iliac crest of healthy normal donors on 10 separate occasions. Bone marrow mononuclear cells were separated on Ficoll gradients (density $1.077 \mathrm{~g} / \mathrm{mL}$ ) by centrifugation at $400 \mathrm{~g}$ for 30 minutes, and then washed 3 times with $\alpha$-MEM, as described previously (11). 
Retroviral vector construction and viral supernatant preparation. $M V N P$ and $M V M$ cDNA clones were generous gifts from Chris Richardson, University of Toronto, Toronto, Canada. A 1.6-kb MVNP cDNA fragment was excised from the pETL-NP\#30 plasmid by digestion with NheI, and was subcloned into the PLXSN retroviral vector (CLONTECH Laboratories Inc., Palo Alto, California, USA) at the XhoI site. The resulting plasmid clone pILXAN\#1 transcribes MVNP mRNA expression under the control of $5^{\prime}$ LTR viral promoter elements. Similarly, the MVM retroviral construct pILXB29M\#2 was developed by subcloning a 1-kb DNA fragment encoding the MVM gene into the $\mathrm{PLXSN}$ vector. The recombinant plasmid constructs were transfected into the PT67 amphotropic packaging cell line using the calcium phosphate method (12). Stable clonal cell lines PT67NP\#2 and PT67-M\#2, producing MVNP and MVM recombinant retrovirus at high titer $\left(10^{6}\right.$ virus particles $/ \mathrm{mL}$ ), were established by selecting for resistance to neomycin $(600 \mu \mathrm{g} / \mathrm{mL})$. Similarly, a PT67-EV control retrovirus producer cell line was established by transfecting the cells with the pLXSN empty vector (EV). Producer cell lines were maintained in DMEM containing $10 \% \mathrm{FBS}, 100 \mathrm{U} / \mathrm{mL}$ each of streptomycin and penicillin, $4 \mathrm{mM}$ L-glutamine, and high glucose $(4.5 \mathrm{~g} / \mathrm{L})$. Retroviral supernatants from the producer cell cultures were collected and filtered $(0.45 \mu \mathrm{m}$ pore diameter $)$ for immediate use. The retrovirus stocks prepared were demonstrated to be helper-free by a marker assay (13). Viral titers present in the culture supernatants were determined by multiplicity of infection of NIH 3T3 fibroblast cells in serial dilutions, and scoring G418-resistant (0.5 mg/mL G418) CFU formed as described (14).

Transduction of buman bone marrow cells. Isolated human bone marrow cells were prestimulated for 1 day in $\alpha$-MEM containing $10 \mathrm{ng} / \mathrm{mL}$ each of IL-3, IL-6, and stem cell factor (R\&D Systems Inc., Minneapolis, Minnesota, USA), and 10\% FBS (GIBCO BRL, Grand Island, New York, USA). After prestimulation, the bone marrow cells were cultured for 96 hours at $37^{\circ} \mathrm{C}$ in a humidified atmosphere of $5 \% \mathrm{CO}_{2}$, at a density of $10^{5}$ cells/mL to $2 \times 10^{5}$ cells $/ \mathrm{mL}$, with supernatant containing the vector. Cultures were supplemented with 4 $\mu \mathrm{g} / \mathrm{mL}$ of polybrene, $20 \mathrm{ng} / \mathrm{mL}$ of IL-3, $50 \mathrm{ng} / \mathrm{mL}$ of IL6 , and $100 \mathrm{ng} / \mathrm{mL}$ of stem cell factor. In preliminary experiments, we determined the cytokine combination that supported the highest transduction efficiency. After 24 hours, the cells were centrifuged and the old supernatant was removed. Freshly prepared viral supernatants supplemented with polybrene and growth factors were added, and cultures were continued for 24 hours. On day 3, cells were harvested for short-term CFU-GM clonogenic assays in methylcellulose (as described below). An aliquot of the cells was evaluated for MVNP expression by immunostaining and Western blot analysis. As a control, some of the cells were cultured under the same experimental conditions, except that viral supernatant containing the EV was added, or no viral supernatant at all was added.
Immunostaining. Monoclonal antibodies that react with the MVNP and the MVM were obtained from Chemicon International (Temecula, California, USA). The cells were fixed with $1 \%$ formaldehyde, and crossreactivity with the various monoclonal antibodies was determined using avidin-biotin-conjugated rabbit antimouse IgG coupled to alkaline phosphatase (VECTASTAIN-ABC-AP kit; Vector Laboratories, Burlingame, California, USA).

Western blot analysis. Normal human bone marrowderived mononuclear cells were transduced with PT67NP\#2 and PT67-M\#2 retroviruses expressing MVNP and MVM proteins respectively, as described above. After 48 hours, cells were washed twice with ice-cold PBS and lysed with SDS sample buffer (62.5 mM Tris$\mathrm{HCl}$ at $\mathrm{pH}$ 6.8, 2\% SDS, 10\% glycerol, $50 \mathrm{mM}$ DTT, and $0.1 \%$ bromophenol blue). The cell lysates $(20 \mu \mathrm{g}$ of protein) were subjected to SDS-PAGE using 10\% gels (BioRad Laboratories, Hercules, California, USA) and blot transferred onto a PVDF membrane (Millipore Corp., Bedford, Massachusetts, USA). After blocking with 5\% skim milk in Tris-buffered saline containing $0.1 \%$ Tween-20 (TBST), the membrane was incubated for 1 hour with sera from patients infected with MV that recognizes both the MVNP and MVM proteins (generously provided by Don Forthal, University of California at Irvine, Irvine, California, USA) at 1:200 dilution in TBST containing 1\% BSA. The blot was then incubated for 1 hour with horseradish peroxidase-conjugated goat anti-rabbit IgG (DAKO Corp., Carpinteria, California, USA), and the bands were revealed by an enhanced chemiluminescence system (Amersham Life Sciences Inc., Arlington Heights, Illinois, USA).

CFU-GM assay in methylcellulose culture. Transduced cells were cultured at $5 \times 10^{3}$ cells/well in $\alpha$-MEM (GIBCO BRL, Grand Island, New York, USA) containing 1.2\% methylcellulose, 30\% FBS, 1\% deionized BSA (Sigma Chemical Co., St. Louis, Missouri, USA), and 100 pg/mL recombinant human GM-CSF (Immunex Corp., Seattle, Washington, USA) with or without $500 \mu \mathrm{g} / \mathrm{mL}$ G418. Transduced cells were plated in a volume of 1.0 $\mathrm{mL}$ in 35-mm culture dishes (Corning, New York, New York, USA), as reported previously (11). The dishes were incubated at $37^{\circ} \mathrm{C}$ in a humidified atmosphere of $5 \%$ $\mathrm{CO}_{2}$ for 7 days. Colonies were scored after 7 days of culture using an inverted microscope, and G418-resistant colonies were individually collected, using finely drawn pipettes, for use in all OCL formation assays.

Long-term cultures for OCL formation. G418-resistant CFU-GM-derived cells $\left(5 \times 10^{3}\right)$, obtained as described above, were cultured in $\alpha$-MEM containing $20 \%$ horse serum, M-CSF $(100 \mathrm{ng} / \mathrm{mL})$, and either $1,25-(\mathrm{OH})_{2} \mathrm{D}_{3}$ $\left(10^{-8} \mathrm{M}\right)$ or RANK ligand $(100 \mathrm{ng} / \mathrm{mL}$; generously provided by Immunex Corp.), in Lab-Tek chamber slides (Nalge Nunc International, Naperville, Illinois, USA). The cultures were fed every 3 days by replacing half the media, and after 14 days or 21 days of culture, the cells were fixed with $1 \%$ formaldehyde and tested for crossreactivity with monoclonal antibody $23 c 6$, which rec- 
ognizes the OCL vitronectin receptor (generously provided by Michael Horton, Rayne Institute, Bone and Mineral Center, London, United Kingdom), using a VECTASTAIN-ABC-AP kit (Vector Laboratories). The 23c6-positive multinucleated cells were scored using an inverted microscope.

Bone resorption assays. Sperm whale dentin slices were sterilized with $70 \%$ ethanol. The transduced cells $(5 \times$ $10^{3}$ ) were cultured for multinucleated cell formation, as described above. When multinucleated cells formed, the media was changed to $\alpha$-MEM and $20 \%$ horse serum containing $1,25-(\mathrm{OH})_{2} \mathrm{D}_{3}\left(10^{-8} \mathrm{M}\right)$. Dentin slices were placed in these cultures, and the cultures were continued for 1 week. To remove the cells, the dentin slices were scrubbed with a toothbrush. The dentin slices were examined by microscopy for formation of resorption lacunae.

$P C R$ amplification of reverse-transcribed $m R N A$. Normal marrow cells, cultured for 2 days with viral supernatants (or after 7 days of culture for CFU-GM), were subjected to RT-PCR analysis for IL-6, 24-hydroxylase, or RANK gene expression as follows. Total RNA from these cells was extracted using RNAzol B solution (TelTest Inc., Friendswood, Texas, USA) and reverse transcribed. Five percent of the first-strand cDNA pool was subjected to PCR amplification using gene-specific PCR primers following standard protocols. The genespecific primers for IL-6 mRNA (GenBank accession number S56892) were 5'-ATG AAC TCC TTC ACA AGC GC-3' (sense) and 5'-GAA GAG CCC TCA GGC TGG ACT G$3^{\prime}$ (antisense). The gene-specific primers for 24-hydroxylase mRNA (GenBank accession number L13286) were 5'-ATT ACC TGA GAA TCA GAG GCC ACG-3' (sense) and 5'-GCC AAA TGC AGT TTA AGC TCT GCT-3' (antisense). The gene-specific primers for RANK mRNA (GenBank accession number AF018253) were 5'-GTC TGC CCT GTG GCC CGG ATG AA-3' (sense) and 5'-GCA AAC GCC AAA GAT GAT GGC AG-3' (antisense). The conditions for amplification were as follows: a 5 -minute initiation step at $94^{\circ} \mathrm{C} ; 35$ cycles at $94^{\circ} \mathrm{C}$ for 1 minute,

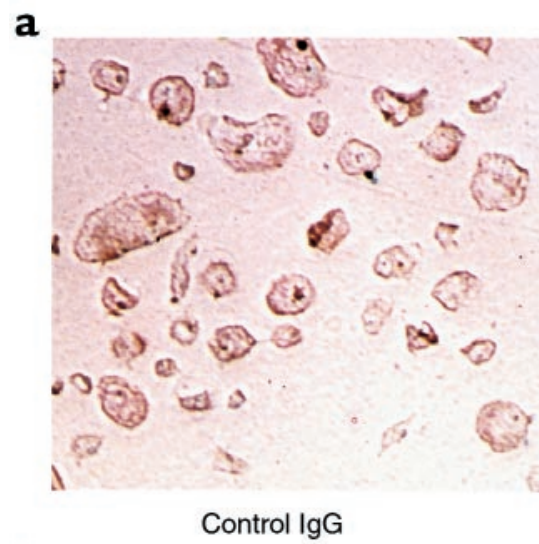

b

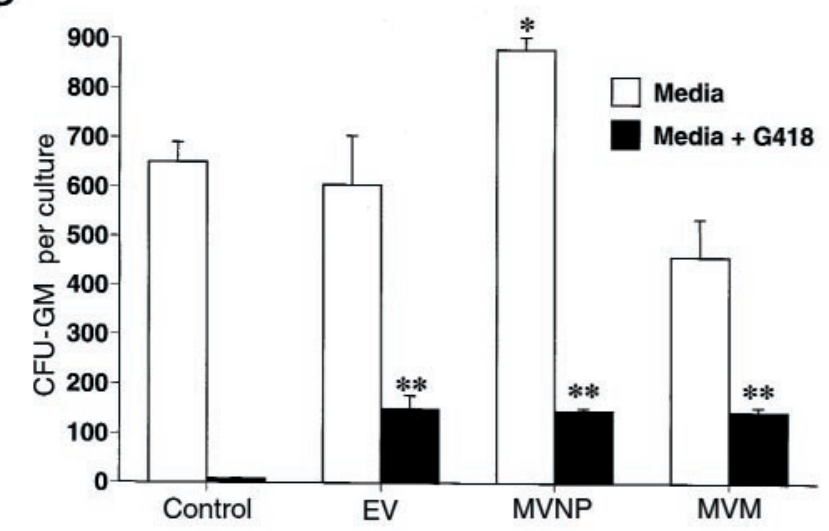

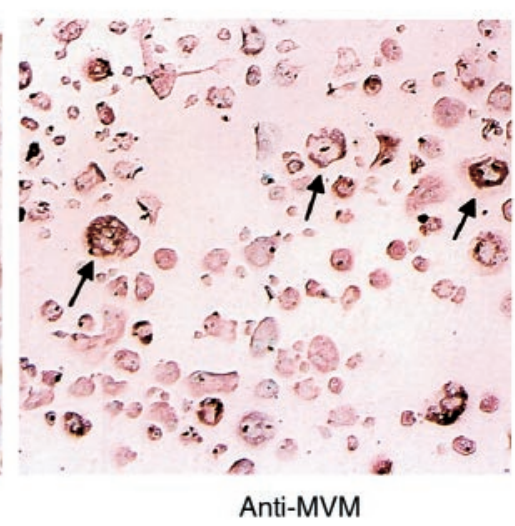

C

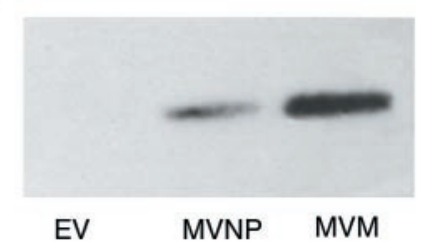

Figure 1

Transduction of OCL precursors. (a) Immunostaining of human bone marrow cells for MV expression. Two days after transduction of the MVNP and MVM genes into human bone marrow cells, gene expression was evaluated by immunostaining using the anti-MVNP and anti-MVM monoclonal antibodies. The dark staining denotes positive reactivity. A similar pattern of immunostaining was detected in 3 separate experiments. (b) CFU-GM colony formation from transduced normal human bone marrow cells. The cells were cultured for CFU-GM, the earliest identifiable OCL precursor, with or without G418 $(500 \mu \mathrm{g} / \mathrm{mL})$. Transduction efficiency was assayed by counting developed CFU-GM on day 7. Results represent those from a typical experiment. ${ }^{*} P<0.05$ compared with nontransduced cells; ${ }^{*} P<0.01$ compared with nontransduced cells cultured with $500 \mu \mathrm{g} / \mathrm{mL}$ of G418. A similar pattern of results was seen in 5 separate experiments. (c) Western blot analysis for MVNP and MVM gene expression in marrow mononuclear cells transduced with retroviral constructs containing the MVNP or MVM gene. Marrow mononuclear cells were transduced with the MVNP or MVM gene; after 3 days, the cells were lysed and the lysates were subjected to Western blot analysis. MVNP-transduced cells expressed only the MVNP protein, and MVM-transduced cells expressed only the MVM protein. 
$\mathbf{a}$

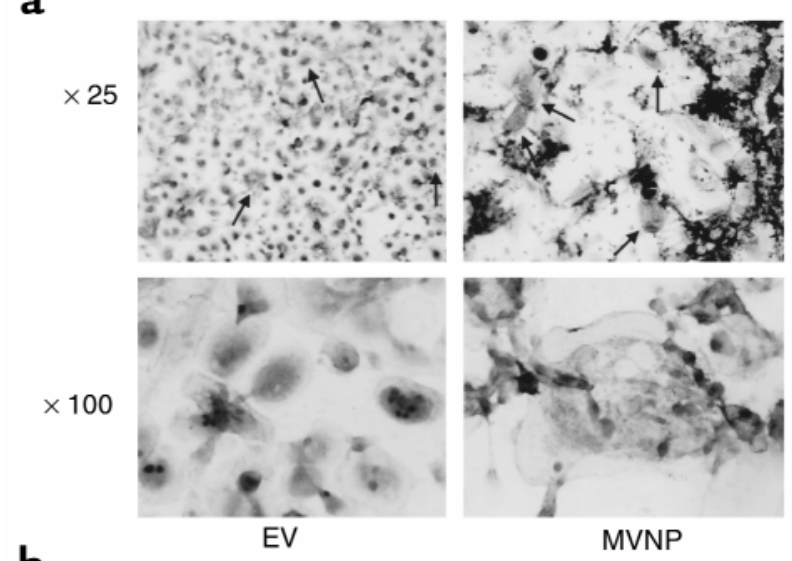

b

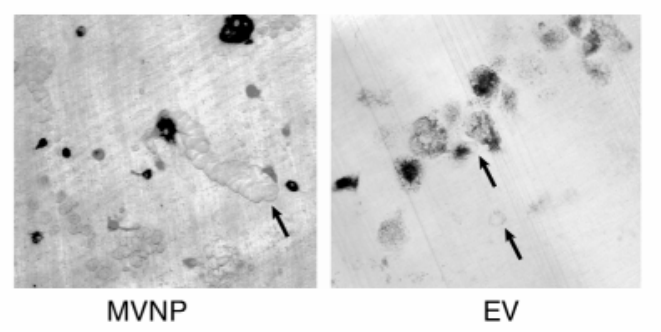

\section{Figure 2}

OCL formation and bone resorption by MVNP-transduced CFUGM-derived cells. (a) Left: Multinucleated cells formed from EV-

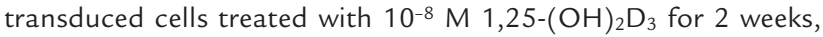
stained with $23 c 6$, a monoclonal antibody that identifies OCLs. Right: Multinucleated cells formed from MVNP-transduced cells

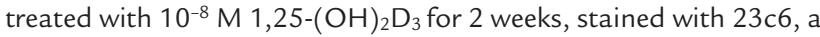
monoclonal antibody that identifies OCLs. Similarly, large multinucleated cells were formed by MVNP-transduced cells in 10 independent experiments. (b) Resorption lacunae on dentin slices formed by multinucleated cells derived from transfected cells. CFUGM-derived cells were cultured with $\left.10^{-8} \mathrm{M} \mathrm{1,25-(OH}\right)_{2} \mathrm{D}_{3}$ as described in Methods. After multinucleated cells formed, dentin slices were added, left for 1 week, and then processed for microscopy $(\times 100)$. Similar results were detected in 2 independent experiments.

$55^{\circ} \mathrm{C}$ for 1 minute, and $72^{\circ} \mathrm{C}$ for 1 minute; and finally an extension step at $72^{\circ} \mathrm{C}$ for 7 minutes. Preliminary experiments demonstrated that these conditions were during the linear phase of the PCR reaction. PCR products were separated by $2 \%$ agarose gel electrophoresis and were revealed with ethidium bromide staining under ultraviolet light. The relative amounts of RANK mRNA expressed were determined by densitometry and compared with $\beta$-actin mRNA expression levels.

Electrophoretic mobility shift assay. Nuclear extracts were prepared from CFU-GM-derived cells $\left(10^{6}\right)$ as described by Dignam and coworkers (15). The sequence of the NF-KB-binding oligonucleotide used as a radioactive DNA probe was 5'-AGT TGA GGG GAC TTT CCC AGG-3'. The DNA binding reaction was performed at room temperature in a volume of $15 \mu \mathrm{L}$, which contained the binding buffer $(10 \mathrm{mM}$ Tris- $\mathrm{HCl}$ at $\mathrm{pH} 7.5$, $0.5 \mathrm{mM}$ EDTA, $1 \mathrm{mM} \mathrm{MgCl}_{2}$, $4 \%$ glycerol, $50 \mathrm{mM} \mathrm{NaCl}$, and $0.5 \mathrm{mM}$ DTT), $50 \mu \mathrm{g} / \mathrm{mL}$ of poly (dI-dC), $10^{5} \mathrm{cpm}$
${ }^{32} \mathrm{P}-$ labeled probe, and $8 \mu \mathrm{g}$ of nuclear proteins in the presence or absence of 50-fold excess unlabeled probe. After incubation for 20 minutes, the samples were electrophoresed on native $6 \%$ acrylamide, $10 \mathrm{mM}$ Trisglycine ( $\mathrm{pH}$ 8.6) gels. The gels were dried and exposed to $x$-ray film overnight.

Statistics. Transduction efficiency was determined by calculating the ratio of the number of CFU-GM colonies that formed in the presence of G418 to the number that formed in the absence of G418. The results of transduction and culture assays are reported as mean $\pm \mathrm{SD}$. Significance was evaluated using a 2 sided, unpaired Student's $t$ test, with $P<0.05$ considered significant. Experiments using bone marrow cells from 10 of 10 separate normal marrow donors showed a similar pattern of results.

\section{Results}

Transduction of OCL precursors. Two days after transduction of the MVNP gene into human bone marrow cells, MVNP gene expression was evaluated by immunostaining; $10-15 \%$ of the cells cross-reacted with the anti-MVNP monoclonal antibody (Figure 1a). The cells were then cultured for CFU-GM, the earliest identifiable OCL precursor, with or without G418 (500 $\mu \mathrm{g} / \mathrm{mL})$. Transduction efficiency as assessed on day 7 of CFU-GM colony formation was approximately $20 \%$ (Figure 1b). Almost all of the nontransduced cells were killed by treatment of the cultures with $500 \mu \mathrm{g} / \mathrm{mL}$ of G418 (Figure 1b). Western blot analysis confirmed that the transduced cells expressed the appropriate MV protein (Figure 1c).

$O C L$ formation and bone resorption by MVNP- and MVMtransduced, CFU-GM-derived cells. Treatment of MVNPtransduced cells with $1,25-(\mathrm{OH})_{2} \mathrm{D}_{3}$ (Table 1) significantly increased the number of OCL-like multinucleated cells, as determined by their cross-reactivity with the $23 \mathrm{c} 6$ monoclonal antibody, and the number of nuclei per multinucleated cell formed by the MVNP-transduced cells (Table 1). The MVM-transduced cells and normal bone marrow cells formed similar numbers of multinucleated cells after 3 weeks (Table 1). Furthermore, the multinucleated cells formed by $M V N P$-transduced human bone marrow cells were morphologically different than nontrans-

\section{Table 1}

Multinucleated cell formation by transduced mononuclear cells

\begin{tabular}{ccc}
\hline & Nuclei per & 23c6-positive MNC \\
& 23c6-positive MNC & MNC per culture \\
EV & $15.4 \pm 7.4$ & $67.7 \pm 10.8$ \\
MVNP & $37.3 \pm 9.7^{\mathrm{A}}$ & $116.0 \pm 22.5^{\mathrm{A}}$ \\
MVM & $19.7 \pm 6.1$ & $76.7 \pm 8.9$
\end{tabular}

The transduced mononuclear cells were cultured for multinucleated cell (MNC) formation in the presence of $\left.10^{-8} \mathrm{M} \mathrm{1,25-(OH}\right)_{2} \mathrm{D}_{3}$. Results are reported as mean $\pm \mathrm{SEM}$. The results for nuclei per 23c6-positive MNC were for 50 MNC counted at random in 4 separate cultures from a typical experiment. Similar results were seen in 10 independent experiments. ${ }^{A}$ Significantly different from EV or MVM cell cultures; $P<0.01$ 

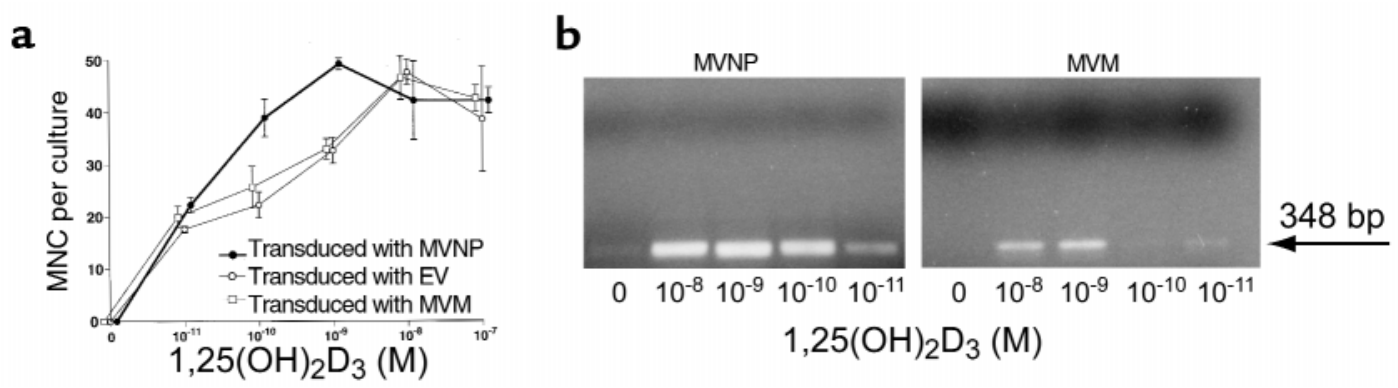

\begin{abstract}
Figure 3
$1,25-(\mathrm{OH})_{2} \mathrm{D}_{3}$ sensitivity of MVNP- and MVM-transduced CFU-GM-derived cells. (a) Effects of 1,25- $(\mathrm{OH})_{2} \mathrm{D}_{3}$ on multinucleated cell formation by CFU-GM-derived cells transduced with MVNP, MVM, or EV. The transduced cells ( $10^{5}$ cells/well) were cultured for multinucleated cell formation in the presence of $10^{-11} \mathrm{M}$ to $10^{-8} \mathrm{M}$ of 1,25-(OH $)_{2} \mathrm{D}_{3}$ as described in Methods. After 2 weeks of culture, the cells were fixed and then stained with the $23 c 6$ monoclonal antibody, which identifies OCLs. The results are expressed as mean \pm SD for triplicate cultures from a typical experiment. A similar pattern of results was seen in 10 independent experiments. (b) Expression of 24-hydroxylase mRNA in $\mathrm{OCL}$ precursors. Each type of transduced cell was treated with $10^{-11} \mathrm{M}$ to $10^{-8} \mathrm{M}$ of $1,25-(\mathrm{OH})_{2} \mathrm{D}_{3}$ and media alone for 3 days. Total RNA was extracted from the cells and subjected to reverse transcription using random primers. The first-strand cDNAs were submitted for PCR analysis for 24-hydroxylase with the specific primers. PCR was performed for 35 cycles. PCR products were separated by electrophoresis on $2 \%$ agarose gels, and the 348 -bp product was revealed with ethidium bromide staining under ultraviolet light. Similar results were detected in 2 independent experiments.
\end{abstract}

duced and EV- and MVM-transduced cells (Figure 2a). The multinucleated cells formed by MVNP-transduced cells contained many more nuclei per 23c6-positive multinucleated cell, and were much larger than multinucleated cells derived from EV- or MVM-transduced or nontransduced normal bone marrow cells. In contrast, there was no significant change in levels of OCL formation or OCL morphology between MVM-transduced and normal human bone marrow cells transduced with the EV.

Furthermore, the resorptive capacity of multinucleated cells formed by MVNP-transduced cells treated with $1,25-(\mathrm{OH})_{2} \mathrm{D}_{3}$ was significantly increased (5-fold) compared with cells transduced with the $M V M$ gene or the $\mathrm{EV}$, or nontransduced cells. The number of resorption lacunae on MVNP- and EV-transfected cells was $50 \pm 8$ and $10 \pm 2$ (mean \pm SEM), respectively. Very large resorption lacunae were formed by $M V N P$-transduced cells on the surface of dentin slices (Figure 2b).

$1,25-(\mathrm{OH})_{2} \mathrm{D}_{3}$ sensitivity of MVNP- and MVM-transduced CFU-GM-derived cells. The MVNP-transduced cells demonstrated enhanced $1,25-(\mathrm{OH})_{2} \mathrm{D}_{3}$ sensitivity. The maximum OCL numbers formed by $M V N P$-transduced cells occurred at concentrations of $1,25-(\mathrm{OH})_{2} \mathrm{D}_{3}$ between $10^{-9}$ and $10^{-10} \mathrm{M}$. MVNP-transduced cells formed OCLs at concentrations of $1,25-(\mathrm{OH})_{2} \mathrm{D}_{3}$ that were $1 \log$ lower than that required for EV- or MVMtransduced cells (Figure 3a).

To confirm that the enhanced sensitivity of the $M V N P$-transduced cells to $1,25-(\mathrm{OH})_{2} \mathrm{D}_{3}$ was an intrinsic property of the cells, and one that was mediated by the vitamin D receptor, 24-hydroxylase mRNA expression in response to $1,25-(\mathrm{OH})_{2} \mathrm{D}_{3}$ was measured in the transduced cells. When $1,25-(\mathrm{OH})_{2} \mathrm{D}_{3}$ binds vitamin $\mathrm{D}$ receptor, 24-hydroxylase is the first enzyme induced (16). Expression of 24-hydroxylase mRNA was induced in MVNP-transduced cells at concentrations of 1,25$(\mathrm{OH})_{2} \mathrm{D}_{3}$ that were at least $1 \log$ less than that required for its expression in $M V M$-transduced cells (Figure 3b) and EV-transduced cells (data not shown).

Expression of RANK and secretion of IL- 6 by MVNP- and MVM-transduced mononuclear cells. To help determine the mechanism responsible for the increased OCL formation by $M V N P$-transduced cells, we examined the expression of RANK and IL- 6 by MVNP-transduced cells. RANK is expressed on committed OCL precursors and is critical for OCL formation $(17,18)$. Furthermore, IL-6 is expressed at high levels by pagetic OCLs, but not by normal OCLs, and may act as an autocrine factor to increase OCL formation in patients with Paget's disease (19). IL-6 also increases proliferation of early OCL precursors (20). Total RNA isolated from the

Table 2

Effects of 1,25- $(\mathrm{OH})_{2} \mathrm{D}_{3}$ on IL-6 released into conditioned media from cultures of transduced marrow

\begin{tabular}{|c|c|c|c|c|c|c|}
\hline \multirow[t]{2}{*}{ Time } & \multicolumn{2}{|c|}{ EV } & \multicolumn{2}{|c|}{$M V N P$} & \multicolumn{2}{|c|}{$M V M$} \\
\hline & Vehicle & $1,25-(\mathrm{OH})_{2} \mathrm{D}_{3}$ & Vehicle & $1,25-(\mathrm{OH})_{2} \mathrm{D}_{3}$ & Vehicle & $1,25-(\mathrm{OH})_{2} \mathrm{D}_{3}$ \\
\hline $0-7$ days & $<10$ & $<10$ & 25 & 32 & $<10$ & 22 \\
\hline 8-14 days & $<10$ & $<10$ & 68 & 125 & 63 & 97 \\
\hline
\end{tabular}

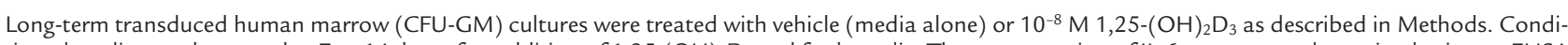
tioned media were harvested at 7 to 14 days after addition of 1,25- $(\mathrm{OH})_{2} \mathrm{D}_{3}$ and fresh media. The concentration of IL-6 present was determined using an ELISA kit for human IL-6 (R\&D Systems Inc.). Results are reported as IL-6 concentration ( $\mathrm{pg} / \mathrm{mL})$ and are the mean of duplicate samples. A similar pattern of results was seen in 2 independent experiments. 
a

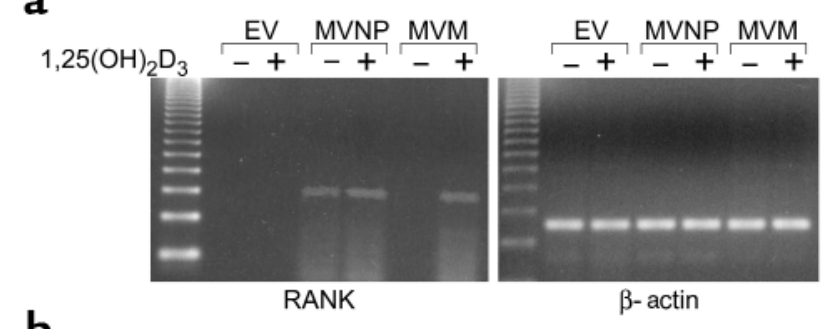

b
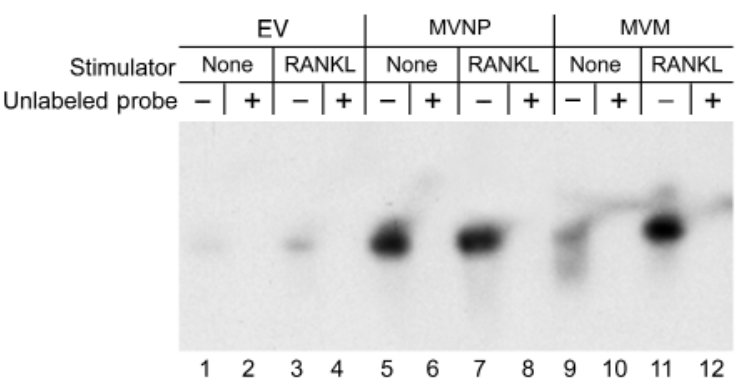

\section{Figure 4}

Expression of RANK $m$ RNA and activation of NF- $\kappa B$ by RANK ligand. (a) Total RNA was extracted from each type of transduced cell, then left untreated or treated with $10^{-8} \mathrm{M} 1,25-(\mathrm{OH})_{2} \mathrm{D}_{3}$ for 2 days. The RNA was subjected to reverse transcription with random primers. The firststrand cDNAs were submitted for PCR analysis for RANK using the specific primers. PCR was performed for 35 cycles. PCR products were separated by electrophoresis on $2 \%$ agarose gels and revealed by ethidium bromide staining under ultraviolet light. Similar results were obtained in 5 independent experiments. (b) Activation of NF- $\mathrm{KB}$. Transduced cells were pretreated with vehicle or $50 \mathrm{ng} / \mathrm{mL}$ RANK ligand (RANKL) for 30 minutes. The nuclear extract was prepared and analyzed by an EMSA with an NF-KB oligonucleotide probe, as described in Methods. The results were similar in 3 independent experiments. Lane 1: Cells transduced with EV. Lane 2: Cells transduced with EV, with 50-fold excess unlabeled probe added as competitor. Lane 3: Cells transduced with EV and treated with RANK ligand. Lane 4: Cells transduced with EV and treated with RANK ligand and 50-fold excess unlabeled probe added as competitor. Lane 5: Cells transduced with MVNP. Lane 6: Cells transduced with MVNP, with 50-fold excess unlabeled probe added as competitor. Lane 7: Cells transduced with MVNP and treated with RANK ligand. Lane 8: Cells transduced with MVNP and treated with RANK ligand and 50-fold excess unlabeled probe added as competitor. Lane 9: Cells transduced with MVM. Lane 10: Cells transduced with MVM, with 50fold excess unlabeled probe added as competitor. Lane 11: Cells transduced with MVM and treated with RANK ligand. Lane 12: Cells transduced with $M V M$, treated with RANK ligand and 50-fold excess unlabeled probe added as competitor.

$M V N P-, M V M-$, and EV-transduced cells was analyzed by RT-PCR using primers specific for RANK. RANK mRNA was detected in the MVNP-transduced cells in the absence of $1,25-(\mathrm{OH})_{2} \mathrm{D}_{3}$ after 2 days of culture (Figure 4a). In contrast, $M V M$-transduced cells required treatment with $1,25-(\mathrm{OH})_{2} \mathrm{D}_{3}$ to induce expression of RANK after 2 days of culture (Figure 4a). As expected, RANK mRNA was detected in all cells after 7 days of culture with $1,25-(\mathrm{OH})_{2} \mathrm{D}_{3}$ (data not shown). In 3 independent experiments, the ratio of RANK mRNA in $M V N P$-transduced cells to RANK mRNA in MVMtransduced cells was $6.4 \pm 0.6$. Treatment of MVNPtransduced cells with $1,25-(\mathrm{OH})_{2} \mathrm{D}_{3}$ increased RANK
mRNA expression just $1.6 \pm 0.3$-fold compared with untreated cells. In contrast, treatment of $M V M$-transduced cells with $1,25-(\mathrm{OH})_{2} \mathrm{D}_{3}$ increased RANK mRNA expression $7.3 \pm 0.6$-fold compared with untreated cells. The ratio of RANK mRNA expression in MVNP- and $M V M$-transduced cells treated with $1,25-(\mathrm{OH})_{2} \mathrm{D}_{3}$ was similar (1.4 \pm 0.3 -fold). RANK mRNA expression levels in EV-transduced cells were at the limits of detection of the densitometer.

IL-6 was detected in MVNP-transduced cell-conditioned media in cultures lacking $1,25-(\mathrm{OH})_{2} \mathrm{D}_{3}$, but was detected in $M V M$-transduced cell-conditioned media after 7 days of culture only when they were treated with $1,25-(\mathrm{OH})_{2} \mathrm{D}_{3}$. Cells transduced with the EV did not release IL- 6 into the conditioned media in significant amounts (Table 2). After 14 days of culture, MVNP- and $M V M$-transduced cells released IL-6 in cultures lacking $1,25-(\mathrm{OH})_{2} \mathrm{D}_{3}$.

Activation of NF- $\kappa B$ by RANK. We then determined if the increased expression of RANK by MVNP-transduced cells in the absence of RANK ligand resulted in greater activation of NF- $\mathrm{KB}$ than that resulting from increased expression of RANK by $M V M$-transduced cells. Enhanced expression of RANK in MVNP-transduced cells activated NF- KB to similar levels in the absence of RANK ligand and when prestimulated with RANK ligand for 30 minutes (Figure 4b, lanes 5 and 7). In contrast, addition of RANK ligand was required to activate NF- $\kappa B$ in EV-transduced cells (Figure 4b, lanes 1 and 3). $M V M$-transduced cells expressed lower levels of NF- $\mathrm{KB}$ than did MVNP-transduced cells in the absence of RANK ligand; addition of RANK ligand increased NF- $\kappa B$ activation 2- to 3-fold (Figure 4b, lanes 9 and 11).

\section{Discussion}

OCLs from individuals with Paget's disease contain nuclear and cytoplasmic inclusions that have been reported to cross-react with antibodies to nucleocapsids from paramyxoviruses, including MV, respiratory syncytial virus, and canine distemper virus (4-8). Our previous studies have suggested that MV is the most common virus detectable in the patients we have studied. However, it has not been determined whether these inclusions represent chronic paramyxoviral infection of cells in the OCL lineage, or whether these viral genes have any pathologic role in Paget's disease. Our data suggest that OCLs formed by normal OCL precursors that express the $M V N P$ gene have many of the characteristics of OCLs from patients with Paget's disease. Compared with OCLs from nontransduced cells, OCLs formed from normal OCL precursors transduced with the MVNP gene have increased numbers of nuclei per multinucleated cell, increased sensitivity to 1,25 $(\mathrm{OH})_{2} \mathrm{D}_{3}$, increased bone-resorbing capacity, enhanced IL-6 production, increased RANK expression, and demonstrate increased OCL formation. In contrast, expression of the MVM gene in normal OCL precursors did not induce formation of OCLs that differ from nor- 
mal OCLs except in their capacity to produce IL- 6 and to express RANK mRNA. The mechanisms responsible for the abnormalities in OCLs induced by the MVNP gene are unclear. Increased OCL formation could result from upregulation of RANK expression and increased expression of IL- 6 by OCL precursors.

Normal OCL precursors transduced with the MVNP gene or the $M V M$ gene demonstrated increased NF- $\mathrm{KB}$ signaling in the absence of RANK ligand. However, the level of NF- $\mathrm{KB}$ signaling in the absence of RANK ligand was not sufficient to induce OCL formation when MCSF was added to the cultures (data not shown). RANK ligand is a critical OCL differentiation factor that, at doses of $10-100 \mathrm{ng} / \mathrm{mL}$ in combination with M-CSF, induces OCL formation. RANK ligand may mediate the effects of most osteotropic factors on OCL formation $(17,18)$. Anderson and coworkers $(21)$ have reported that overexpression of RANK in 293 cells is sufficient to activate NF- $\kappa \mathrm{B}$ in a ligand-independent manner. Increased expression of RANK in normal OCL precursors transduced with the MVNP gene may be responsible for NF- $\mathrm{KB}$ signaling in the absence of RANK ligand. This increased NF- $K B$ signaling could result in an enhanced differentiation potential of bipotent early OCL precursors toward the OCL lineage in the presence of appropriate osteotropic factors, rather than toward the mature monocytic lineage. Alternatively, other cytokines such as IL- 6 or TNF- $\alpha$ also signal through NF- $\mathrm{\kappa B}$, and could be responsible for the increased NF- $\mathrm{KB}$ signaling in $M V N P$ - and $M V M$-transduced cells in the absence of RANK ligand.

We have shown previously that IL-6 appears to be an autocrine/paracrine factor that stimulates OCL formation in patients with Paget's disease (19). IL-6 levels are markedly increased in the marrow from patients with Paget's disease compared with normal individuals, and IL-6 induces OCL formation (22). Furthermore, De La Mata et al. (23) have shown in vivo that IL-6 stimulates expansion of the OCL precursor pool, which can then interact with low levels of osteoclastogenic factors (such as PTHrP) that induce OCL precursor differentiation and markedly increase OCL formation. Other workers have shown that infection of cells in the monocyte lineage with $\mathrm{MV}$ results in marked upregulation of IL- 6 production, with little or no production of IL- $1 \beta$ or TNF- $\alpha$ (24). Taken together, these data suggest a role for IL-6 in the expansion of the OCL precursor pool in Paget's disease, and further suggest that the MVNP gene may be responsible in part for the enhanced IL- 6 production by OCLs from Paget's patients.

OCL precursors transduced with the MVNP gene also showed increased sensitivity to $1,25-(\mathrm{OH})_{2} \mathrm{D}_{3}$, analogous to OCL precursors from patients with Paget's disease (25). We have shown that enhanced sensitivity to $1,25-(\mathrm{OH})_{2} \mathrm{D}_{3}$ is an intrinsic property of OCL precursors from Paget's patients, and that it may result from increased affinity of the vitamin $\mathrm{D}$ receptor for 1,25 $(\mathrm{OH})_{2} \mathrm{D}_{3}(26)$. Similarly, OCL precursors transduced with the MVNP gene showed increased expression of 24-hydroxylase mRNA in response to $1,25-(\mathrm{OH})_{2} \mathrm{D}_{3}$. 24-hydroxylase is the first gene induced when 1,25$(\mathrm{OH})_{2} \mathrm{D}_{3}$ binds to vitamin $\mathrm{D}$ receptor, and these results demonstrate that the enhanced sensitivity of normal OCL precursors transduced with the MVNP gene was mediated by vitamin $\mathrm{D}$ receptor. However, the mechanism responsible for the enhanced sensitivity to 1,25 $(\mathrm{OH})_{2} \mathrm{D}_{3}$ in normal OCL precursors transduced with the MVNP gene is unclear. Possibly, the MVNP gene product induces a coactivator or inhibits a corepressor of vitamin D receptor. Liston et al. (27) demonstrated that MVNP proteins can interact with a variety of cellular proteins. Immunoprecipitation studies using glutathione $S$-transferase nucleocapsid protein constructs demonstrated that MVNP interacted specifically with at least 12 cellular proteins.

In summary, our data support a potential pathophysiologic role for MV in the abnormal OCL morphology and activity in patients with Paget's disease. In particular, our data suggest that expression of the MVNP gene is important. However, we cannot state that these changes are unique to expression of the MVNP gene, because we did not test other viral nucleocapsid genes. Further studies are required to delineate the molecular mechanisms responsible for the effects of MVNP protein on OCL activity in these patients.

\section{Acknowledgments}

The authors thank Bibi Cates for preparation of the manuscript. This work was supported by research funds from the Veterans Administration; National Institutes of Health grants AG-13625, AR-41336, DE 12603, and AR-44603; and grant CA40035 from the National Cancer Institute.

1. Hosking, D.J. 1981. Paget's disease of bone. Br. Med. J. (Clin. Res. Ed.). 283:686-688.

2. Yates, A.J.P. 1988. Paget's disease of bone. Baillieres Clin. Endocrinol. Metab. 2:267-295.

3. Kukita, A., Chenu, C., McManus, L.M., Mundy, G.R., and Roodman, G.D. 1990. Atypical multinucleated cells form in long-term marrow cultures from patients with Paget's disease. J. Clin. Invest. 85:1280-1286.

4. Mills, B.G., et al. 1984. Evidence for both respiratory syncytial virus and measles virus antigens in the osteoclasts of patients with Paget's disease of bone. Clin. Orthop. Relat. Res. 183:303-311.

5. Basle, M.F., et al. 1985. Paramyxovirus antigens in osteoclasts from Paget's bone tissue detected by monoclonal antibodies. J. Gen. Virol. 66:2103-2110.

6. Gordon, M.T., Mee, A.P., Anderson, D.C., and Sharpe, P.T. 1995. Canine bone marrow cultures infected with canine distemper virus: an in vitro model of Paget's disease. Bone. 19:461S-466S.

7. Mills, B.G., Singer, F.R., Weiner, L.P., and Holst, P.A. 1981. Immunohistochemical demonstration of respiratory syncytial virus antigens in Paget's disease of bone. Proc. Natl. Acad. Sci. USA. 78:1209-1213.

8. Basle, M.F., Fournier, J.G., Rozenblatt, S., Rebel, A., and Bouteille, M. 1986. Measles virus RNA detected in Paget's disease bone tissue by in situ hybridization. J. Gen. Virol. 67:907-913.

9. Gordon, M.T., Anderson, D.C., and Sharpe, P.T. 1991. Canine distemper virus localized in bone cells of patients with Paget's disease. Bone. 12:195-201.

10. Reddy, S.V., Singer, F.R., Mallette, L., and Roodman, G.D. 1996. Detection of measles virus nucleocapsid transcripts in circulating blood cells and hematopoietic progenitors from patients with Paget's disease. J. Bone Miner. Res. 11:1602-1607.

11. Kurihara, N., Chenu, C., Miller, M., Civin, C.I., and Roodman, G.D. 1990. Identification of committed mononuclear precursors for osteoclast-like cells formed in long-term marrow cultures. Endocrinology. 126:2733-2741.

12. Graham, F.L., and van der Eb, A.J. 1973. A new technique for the assay of infectivity of human adenovirus 5 DNA. Virology. 52:456-467. 
13. Miller, A.D., and Buttimore, C. 1986. Redesign of retrovirus packaging cell lines to avoid recombination leading to helper virus production. Mol. Cell. Biol. 6:2895-2902.

14. Ausubel, F.M., et al. 1994. Current protocols in molecular biology. Volume 9. John Wiley \& Sons. New York, NY. 4-9.

15. Dignam, J.D., Lebovitz, R.M., and Roeder, R.G. 1983. Accurate transcription initiation by RNA polymerase II in a soluble extract from isolated mammalian nuclei. Nucleic Acids Res. 11:1475-1489.

16. Ohyama, Y., et al. 1994. Identification of a vitamin D-responsive element in the 5'-flanking region of the rat 25-hydroxyvitamin $\mathrm{D}_{3}$ 24-hydroxylase gene. J. Biol. Chem. 269:10545-10550.

17. Yasuda, H., et al. 1998. Osteoclast differentiation factor is a ligand for osteoprotegerin/osteoclastogenesis-inhibitory factor and is identical to TRANCE/RANKL. Proc. Natl. Acad. Sci. USA. 95:3597-3602.

18. Capparelli, C., et al. 1998. Osteoprotegerin ligand is a cytokine that regulates osteoclast differentiation and activation. Cell. 93:165-176.

19. Roodman, G.D., et al. 1992. Interleukin-6: a potential autocrine/paracrine factor in Paget's disease of bone. J. Clin. Invest. 89:46-52.

20. Hoyland, J.A., Freemont, A.J., and Sharpe, P.T. 1994. Interleukin-6, IL-6 receptor, and IL-6 nuclear factor gene expression in Paget's disease. J. Bone
Miner. Res. 9:75-80.

21. Anderson, D.M., et al. 1997. A homologue of the TNF receptor and its ligand enhance T-cell growth and dendritic-cell function. Nature 390:175-179.

22. Kurihara, N., Bertolini, D., Suda, T., Akiyama, Y., and Roodman, G.D. 1990. IL-6 stimulates osteoclast-like multinucleated cell formation in long-term human marrow cultures by inducing IL-1 release. J. Immunol. 144:4226-4230.

23. De La Mata, J., et al. 1995. IL-6 enhances hypercalcemia and bone resorption mediated by PTH-rP in vivo. J. Clin. Invest. 95:2846-2852.

24. Karp, C.L., et al. 1996. Mechanism of suppression of cell-mediated immunity by measles virus. Science. 273:228-231.

25. Demulder, A., Takahashi, S., Singer, F.R., Hosking, D.J., and Roodman, G.D. 1993. Evidence for abnormalities in osteoclast precursors and the marrow microenvironment in Paget's disease. Endocrinology. 133:1978-1982.

26. Menaa, C., et al. 2000. 1,25-dihydroxyvitamin $\mathrm{D}_{3}$ hypersensitivity of osteoclast precursors from patients with Paget's disease. J. Bone Miner. Res. In press.

27. Liston, P., Batal, R., DiFlumeri, C., and Briedis, D.J. 1997. Protein interaction domains of the measles virus nucleocapsid protein. Arch. Virol. 142:305-321. 